\title{
Studies on Pyrolysis Kinetic of Newspaper Wastes in a Packed Bed Reactor: Experiments, Modeling, and Product Characterization
}

\author{
Aparna Sarkar, ${ }^{1}$ Sudip De Sarkar, ${ }^{1}$ Michael Langanki, ${ }^{2}$ and Ranjana Chowdhury ${ }^{1}$ \\ ${ }^{1}$ Chemical Engineering Department, Jadavpur University, Kolkata 700 032, India \\ ${ }^{2}$ Engler Bunte Institute (Gas Erdol Kohle), Karlsruhe University, 76133 Karlsruhe, Germany
}

Correspondence should be addressed to Ranjana Chowdhury; ranjana.juchem@gmail.com

Received 31 July 2014; Revised 8 December 2014; Accepted 9 December 2014

Academic Editor: S. Venkata Mohan

Copyright (C) 2015 Aparna Sarkar et al. This is an open access article distributed under the Creative Commons Attribution License, which permits unrestricted use, distribution, and reproduction in any medium, provided the original work is properly cited.

\begin{abstract}
Newspaper waste was pyrolysed in a $50 \mathrm{~mm}$ diameter and $640 \mathrm{~mm}$ long reactor placed in a packed bed pyrolyser from $573 \mathrm{~K}$ to $1173 \mathrm{~K}$ in nitrogen atmosphere to obtain char and pyro-oil. The newspaper sample was also pyrolysed in a thermogravimetric analyser (TGA) under the same experimental conditions. The pyrolysis rate of newspaper was observed to decelerate above $673 \mathrm{~K}$. A deactivation model has been attempted to explain this behaviour. The parameters of kinetic model of the reactions have been determined in the temperature range under study. The kinetic rate constants of volatile and char have been determined in the temperature range under study. The activation energies $25.69 \mathrm{KJ} / \mathrm{mol}, 27.73 \mathrm{KJ} / \mathrm{mol}, 20.73 \mathrm{KJ} / \mathrm{mol}$ and preexponential factors $7.69 \mathrm{~min}^{-1}, 8.09 \mathrm{~min}^{-1}, 0.853 \mathrm{~min}^{-1}$ of all products (solid reactant, volatile, and char) have been determined, respectively. A deactivation model for pyrolysis of newspaper has been developed under the present study. The char and pyro-oil obtained at different pyrolysis temperatures have been characterized. The FT-IR analyses of pyro-oil have been done. The higher heating values of both pyro-products have been determined.
\end{abstract}

\section{Introduction}

Waste management is a big issue nowadays as wastes are being generated in an ever-increasing rate by growing affluent societies. The large amount of nonhomogeneous municipal solid waste has become a tremendous problem for all Indian metropolitan cities. Municipal solid waste (MSW) consists mainly of household and commercial wastes, which are disposed of by, or on behalf of, a local authority. It is composed mainly of paper/cardboard, plastics, glass, metals, textiles, and food/garden waste. Disposal of the massive waste materials poses problems in terms of environmental impact, economic costs and technology implementation. Environment friendly processes must be thoroughly studied for the utilization of the waste materials in view of the increasing demand of energy in this modern era. The recovery of energy from the waste materials may be done through thermochemical processes like combustion, gasification, and pyrolysis. Among all these routes, pyrolysis has been receiving increasing attention in recent years as an acceptable route for waste to energy conversion. The main reason for this is that, in the pyrolysis process production of either char, oil, or gases, the pyrolysis products may be maximized by the adjustment of process condition. Pyrolysis is a thermochemical process in which hydrocarbon rich solid or liquid feed materials are thermally degraded to char, volatile liquid, and noncondensable gaseous component in absence of oxidizing media either air or oxygen. The mechanism of primary pyrolysis of solid and liquid feedstocks is as follows:

$$
\begin{aligned}
\text { Pyrolysing solid/liquid } \longrightarrow & \text { Char + Liquid (tar) } \\
& + \text { Gas (pyro-gas) }
\end{aligned}
$$

The usual range of pyrolysis temperature is $573 \mathrm{~K}$ to $1273 \mathrm{~K}$. All pyrolysis products have a potential use. For example, char can be burnt as fuel or disposed off (since the heavy metals are fixed inside the carbonaceous matrix), or it can even be upgraded to activated carbon [1]. Gas can be used as fuel [2], 
TABLE 1: Results of proximate and ultimate analyses and higher heating value of newspaper.

\begin{tabular}{lcc}
\hline Properties & $\%(\mathrm{~W} / \mathrm{W})$ & Higher heating value $(\mathrm{MJ} / \mathrm{kg})$ \\
\hline Moisture & 10 & \\
Volatile & 75 & \\
Ash & n.d & \\
Fixed carbon & 15 & 16 \\
Carbon & 59 & \\
Hydrogen & 8.23 & \\
Nitrogen & n.d & \\
Sulfur & 0.31 & \\
Oxygen (by difference) & 32.44 & \\
\hline
\end{tabular}

whereas oil can either serve as fuel or as a raw material for chemicals. The yield of either product, namely, char or tar or gas, may be maximized just by adjustment of operating conditions.

In recent years, a few works have been reported in the literature on pyrolysis of waste newspaper or paper mixture [3-9]. Investigation on pyrolysis of mixture of papers with various types of municipal solid wastes has been reported by a few researchers [10-14].

Data solely concerned with pyrolysis of newspaper is however lacking. According to the aforementioned literature, TGA is a common technique to study the thermal decomposition behavior as well as the chemical kinetics of thermal conversion of several biomasses. Newspaper is the principal organic solid waste of Indian metro cities. The composition of newspaper is $62 \%$ cellulose, $16 \%$ hemicellulose, and $16 \%$ lignin. Newspaper has high heating value of about $16 \mathrm{MJ} / \mathrm{kg}$ and can be converted through pyrolysis route. As the studies of kinetics of pyrolysis of a feedstock are necessary for proper understanding and application of the process, pyrolysis kinetics of newspaper has been investigated in detail under the present study. Mathematical model incorporating deactivation has also been developed.

\section{Experimental}

2.1. Materials. Old newspaper samples were collected from a local residential area for pyrolysis. Table 1 summarizes the results of proximate and ultimate analyses and higher heating value of newspaper.

2.2. Thermogravimetric Analysis. Thermogravimetric analysis (Pyris Diamond) of newspaper sample was conducted in the temperature range of $573 \mathrm{~K}$ to $1173 \mathrm{~K}$, given in Figure 1. The heating rate was $10^{\circ} \mathrm{C} / \mathrm{min}$. The flow rate of $\mathrm{N}_{2}$ gas was $150 \mathrm{~mL} / \mathrm{min}$.

From this figure, it was clear that the pyrolysis of newspaper started at above $473 \mathrm{~K}$ where the weight loss was approximately $20 \%$. Pyrolysis progressed slowly from $473 \mathrm{~K}$ to $573 \mathrm{~K}$ leading to weight loss up to $35 \%$. Above $573 \mathrm{~K}$, pyrolysis became faster up to $773 \mathrm{~K}$ resulting in a weight loss of $74 \%$. This was followed by slow pyrolysis up to $1173 \mathrm{~K}$.

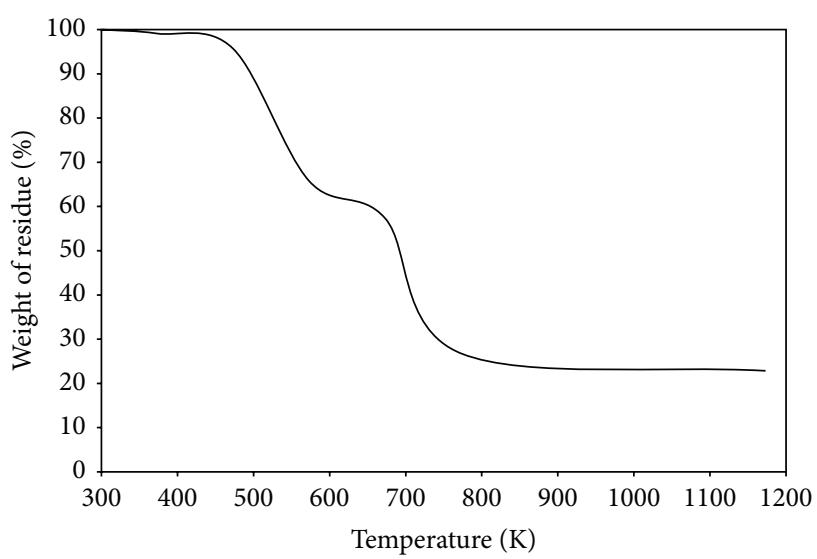

FIgURE 1: Thermogravimetric analysis graph.

The three segments of pyrolysis curve drawn by plotting weight fraction against pyrolysis temperature might signify the pyrolysis of constituent compounds of newspaper, namely, cellulose, hemicelluloses, and lignin. The fractions of cellulose, hemicelluloses, and lignin in newspaper are 40$55 \%, 25-40 \%$, and $18-20 \%$, respectively [15]. It appears that the hemicelluloses part started pyrolysing at $473 \mathrm{~K}$ and the main weight loss occurred for the pyrolysis of hemicellulose portion between $473 \mathrm{~K}$ and $573 \mathrm{~K}$. Pyrolysis of cellulose part started at $573 \mathrm{~K}$ and proceeded up to $773 \mathrm{~K}$. The last segment of the curve belonging to the temperature zone between $773 \mathrm{~K}$ and $1173 \mathrm{~K}$ signified the pyrolysis of lignin part of newspaper. Similar observation has been reported by Williams and Besler [16] during their studies on the pyrolysis of wood and its constituent component.

2.3. Pyrolysis Set-Up. A $50 \mathrm{~mm}$ diameter and $640 \mathrm{~mm}$ long cylindrical stainless steel fixed bed pyrolyser was placed horizontally in a tubular furnace (Figure 2).

The pyrolyser was hung by a stainless steel chain attached with a weighing machine for continuous monitoring of the residual mass of solid in the pyrolyser. The furnace temperature varied from $573 \mathrm{~K}$ to $1173 \mathrm{~K}$. Once the furnace temperature was raised to a preset value, pyrolyser was inserted into the furnace. Isothermal condition was maintained throughout the entire pyrolysis period. Pyrolysis was carried out for one hour at all temperatures. Experiments were designed to investigate the effects of temperature of pyrolysis on yields of pyro-oil and char and their characteristics. Nitrogen was supplied to the pyrolyser throughout the experiment to sweep the volatiles produced during pyrolysis and to maintain inert atmosphere in the reactor. The volatile product stream along with nitrogen was directed to a water cooled condenser and a series of containers placed in an ice bath. Finally, the gas stream was passed through a silica gel bed and was collected in a gas sampling bottle. The organic part of tar which got dissolved in benzene was extracted in a rotary evaporator and the quantity of pyro-oil was established. The higher heating values of the condensed pyro-oil and char samples, 


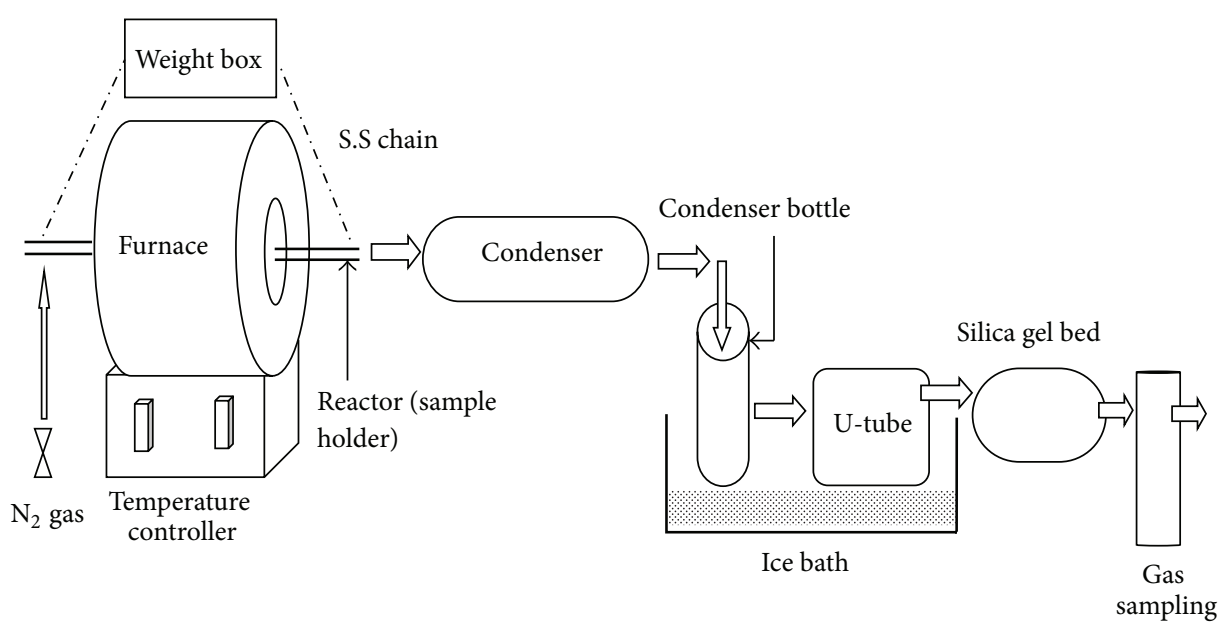

FIGURE 2: Experimental set up.

obtained as pyrolysis products, were determined using bomb calorimeter.

\section{Pyrolysis Kinetics}

Pyrolysis of newspaper sample proceeds through complex reactions in series, parallel, or combination of both. Under the present study, a parallel reaction model has been attempted to describe pyrolysis kinetics of newspaper. According to this model, pyrolysis of newspaper has been considered to be a homogeneous solid phase reaction and the pyrolysis products have been considered to be char-lumped solid and volatiles made up of tar and gaseous product. The reaction pathway of pyrolysis according to the present model is as follows:

$$
\begin{gathered}
\text { Newspaper } \longrightarrow \text { Active complex } \stackrel{k_{v}}{\longrightarrow} \text { Volatile (gas }+ \text { tar) } \\
\stackrel{k_{c}}{\longrightarrow} \text { Char }
\end{gathered}
$$

The reaction kinetics of volatile and char has been elaborately discussed in the studies of pyrolysis of coconut shell [17], vegetable market waste [18], textile wastes [19], sesame oil cake [20], and mustard press cake [21, 22].

Figure 3 shows the experimental weight fraction profile of residue with respect to time in isothermal conditions at $573 \mathrm{~K}, 873 \mathrm{~K}$, and $1173 \mathrm{~K}$, respectively. From close observation of the data, it appears that the pyrolysis reactions proceed considerably in the temperature range of $573 \mathrm{~K}$ to $1173 \mathrm{~K}$. Below this temperature range, the reactions do not occur at an appreciable rate. From the plots, it is also apparent that at each temperature, a quasiequilibrium of the reaction prevails. The rates of devolatilization reactions decline at temperatures above $673 \mathrm{~K}$. Therefore, the values of frequency factors and activation energies of the reactions of reactant decomposition, volatile formation, and char formation are determined by regression analysis of the rate constant determined in the temperature range of $573 \mathrm{~K}$ to $673 \mathrm{~K}$ [17-20]. The frequency

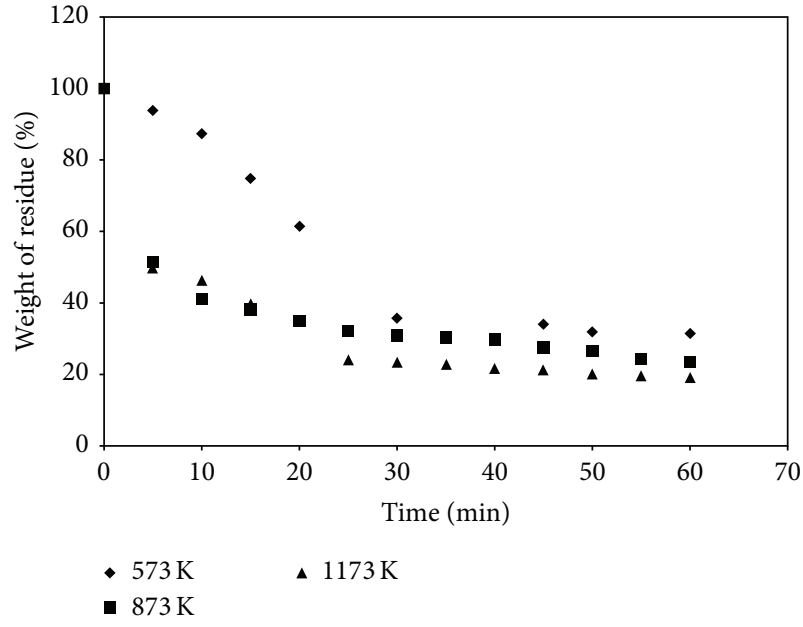

FIGURE 3: Variation of percentage of weight of residue of newspaper sample with respect to time at different pyrolysis temperature.

factors and activation energies of different reactions are given in Table 2.

In Figure 4 , the rate constants $k, k_{v}$, and $k_{c}$, calculated using activation energies and frequency factors reported in Table 2, have been plotted in the logarithmic scale against reciprocal temperature. All the rate constants calculated from the experimental results in the temperature range of 573 to $1173 \mathrm{~K}$ have also been superimposed on the same figure. From the figure, it is apparent that for temperatures higher than $673 \mathrm{~K}$, the actual values of rate constants are far below the predictions of Arrhenius law. The deviation of the pyrolysis rate constants from the Arrhenius law may be due to the deactivation of the solid reactants with temperature. Thus, a deactivation model has been introduced. In the present study, a deactivation model has been developed on the following assumption.

(i) Deactivation occurs with the increase of pyrolysis temperature beyond $673 \mathrm{~K}$. 
TABLE 2: Calculated activation energies and frequency factors as per Arrhenius law.

\begin{tabular}{lcc}
\hline $\begin{array}{l}\text { Reaction rate } \\
\text { constant }\end{array}$ & $\begin{array}{c}\text { Frequency factor } \\
\left(\mathrm{min}^{-1}\right)\end{array}$ & $\begin{array}{c}\text { Activation energy } \\
(\mathrm{kJ} / \mathrm{mol})\end{array}$ \\
\hline$k$ & 7.69 & 25.69 \\
$k_{v}$ & 8.09 & 27.73 \\
$k_{c}$ & 0.853 & 20.73 \\
\hline
\end{tabular}

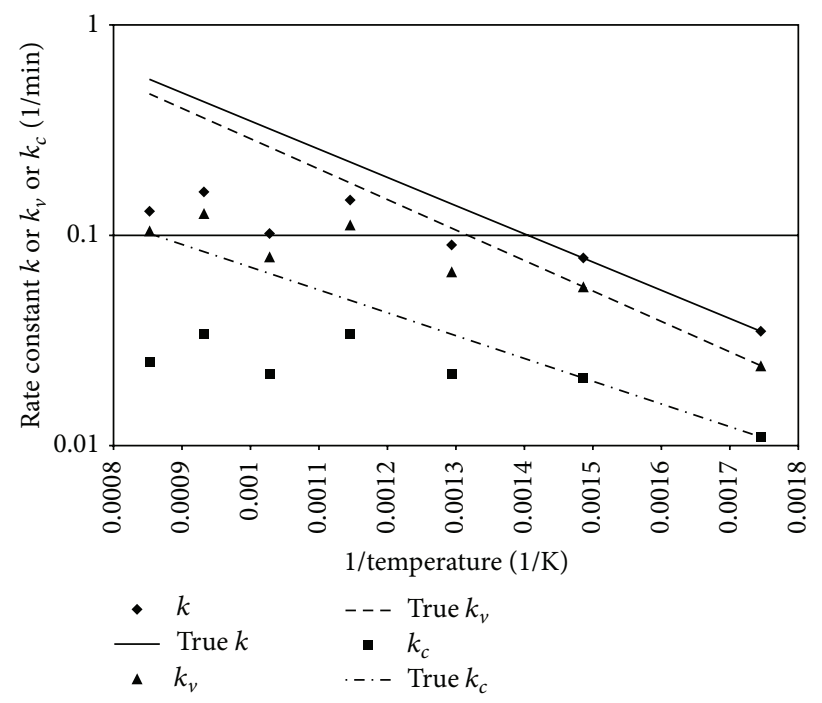

FIgURE 4: Simulated true $k$, true $k_{v}$, true $k_{c}$, and experimental $k$, $k_{v}$, and $k_{c}$ values of rate constant for weight loss of newspaper, volatile formation, and char formation in logarithmic scale against reciprocal temperature.

(ii) The apparent reaction rate constants may be written in the following form:

$$
\begin{gathered}
k_{\mathrm{ap}}=a k_{0} \exp \left(\frac{-E}{R T}\right), \\
k_{v \mathrm{ap}}=a_{v} k_{v 0} \exp \left(\frac{-E_{v}}{R T}\right), \\
k_{\text {cap }}=a_{c} k_{c 0} \exp \left(\frac{-E_{c}}{R T}\right),
\end{gathered}
$$

where $a, a_{v}$, and $a_{c}$ may be defined as the activities of the solid towards corresponding reactions.

(iii) The values of activities $a, a_{v}$, and $a_{c}$ are unity at $673 \mathrm{~K}$ and they decrease to the minimum of zero as the temperature increases to $1273 \mathrm{~K}$.

The normalized temperature parameter has been defined as

$$
\theta=\frac{T-T(a=1)}{T(a=0)-T(a=1)} .
$$

Here, $T(a=1)=673 \mathrm{~K}$ and $T(a=0)=1273 \mathrm{~K}$.
TABLE 3: Values of constant for deactivation model.

\begin{tabular}{lcc}
\hline Model parameters & Values & Correlation coefficient \\
\hline$n$ & -0.067 & 0.897 \\
$n_{v}$ & -0.089 & 0.901 \\
$n_{c}$ & -0.046 & 0.874 \\
\hline
\end{tabular}

3.1. Deactivation Model. In this model, the rates of deactivation are considered as function of activities themselves with exponents other than unity:

$$
\begin{aligned}
& \frac{-d a}{d \theta}=\beta a^{n} \quad(\text { where } n \neq 1), \\
& \frac{-d a_{v}}{d \theta}=\beta_{v} a_{v}^{n_{v}} \quad\left(\text { where } n_{v} \neq 1\right), \\
& \frac{-d a_{c}}{d \theta}=\beta_{c} a_{c}^{n_{c}} \quad\left(\text { where } n_{c} \neq 1\right) .
\end{aligned}
$$

The boundary conditions are as follows:

$$
\begin{array}{ll}
a=a_{v}=a_{c}=0 & \text { at } \theta=1, \\
a=a_{v}=a_{c}=1 & \text { at } \theta=0 .
\end{array}
$$

Applying the boundary conditions represented by (4), the solutions of the differential equations may be expressed as

$$
\begin{aligned}
& a=\exp \left[\frac{\ln (1-\theta)}{1-n}\right], \\
& a_{v}=\exp \left[\frac{\ln (1-\theta)}{1-n_{v}}\right], \\
& a_{c}=\exp \left[\frac{\ln (1-\theta)}{1-n_{c}}\right] .
\end{aligned}
$$

Therefore, the rate expression may be represented as follows:

$$
\begin{gathered}
k_{\text {ap }}=k_{0} \exp \left(\frac{-E}{R T}+\frac{\ln (1-\theta)}{1-n}\right), \\
k_{v a \mathrm{p}}=k_{v 0} \exp \left(\frac{-E_{v}}{R T}+\frac{\ln (1-\theta)}{1-n_{v}}\right), \\
k_{c \text { ap }}=k_{c 0} \exp \left(\frac{-E_{c}}{R T}+\frac{\ln (1-\theta)}{1-n_{c}}\right) .
\end{gathered}
$$

Values of different parameter of deactivation model have been determined using nonlinear regression analysis. The values of parameters are given in Table 3.

In Figure 5, logarithms of simulated values of $k, k_{v}$, and $k_{c}$, predicted by Arrhenius law using data of $573 \mathrm{~K}$ and $673 \mathrm{~K}$ as well as those predicted by deactivation model in the temperature zone beyond $673 \mathrm{~K}$, have been plotted against inverse of temperature.

Comparison with experimental data suggests that for $k$, $k_{v}$, and $k_{c}$, the deactivation model can explain the reality, except at $973 \mathrm{~K}$. The experimental findings at $973 \mathrm{~K}$ indicate comparatively low reaction rate. Actually, other than deactivation of single pyrolysis component due to tar clogging 


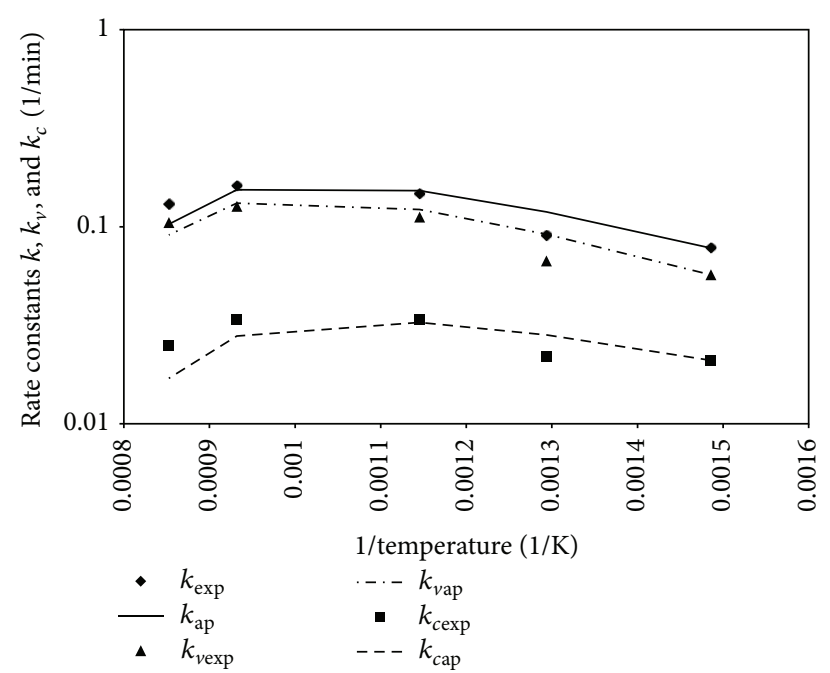

FIGURE 5: Comparison of simulated rate constants $k_{\text {app }}, k_{v a p p}$, and $k_{\text {capp }}$ as per deactivation model with the experimental results $k_{\text {exp }}$, $k_{v \exp } \cdot k_{c \exp }$ for weight loss of newspaper, volatile, and char formation, respectively.

of active sites, conformational changes, and so forth, as observed by Bandyopadhyay et al. [17], Ray et al. [18], Sarkar and Chowdhury [19], use of different types of woods, both soft and hard, as the source of Indian newspaper may lead to abnormal pyrolysis behaviour.

\section{Results and Discussions}

4.1. Effects of Pyrolysis Temperature on Product Yields. After the completion of pyrolysis of newspaper, the solid residue part was collected from the reactor. The unreacted newspaper and the left char yield were determined. While the condensable part of volatile was considered as a tar yield, the organic part of tar, soluble in benzene, was considered as pyro-oil. The gas yield was calculated by subtracting the amount of tar from volatile yield. These yields of char, tar, and gases in relation to reactor temperature are shown in Figure 6.

The char yield decreased with a rise in pyrolysis temperature from $32 \mathrm{wt} \%$ at $573 \mathrm{~K}$ to $20 \mathrm{wt} \%$ at $1173 \mathrm{~K}$. On the other hand, the yield of tar increased to $43 \mathrm{wt} \%$ at $773 \mathrm{~K}$ and then it decreased to $12 \mathrm{wt} \%$ at $1173 \mathrm{~K}$. Figure 6 also shows that while gas yield increased gradually from $573 \mathrm{~K}$ to $873 \mathrm{~K}$, it increased appreciably as the pyrolysis temperature increased from $973 \mathrm{~K}$ to $1173 \mathrm{~K}$.

Appearance of a maximum in the trend of yield of tar against temperature may be due to the commencement of further cracking of tar molecules to lower gaseous molecules at higher temperatures. Under the present experimental conditions, the results showed a clear influence of temperature on the fractional yields of char and volatiles. The decrease in the char yield with pyrolysis temperature is to be attributed to an increasing devolatilization of the solid hydrocarbons in the char. Partial gasification of the carbonaceous residue is also possible [23].

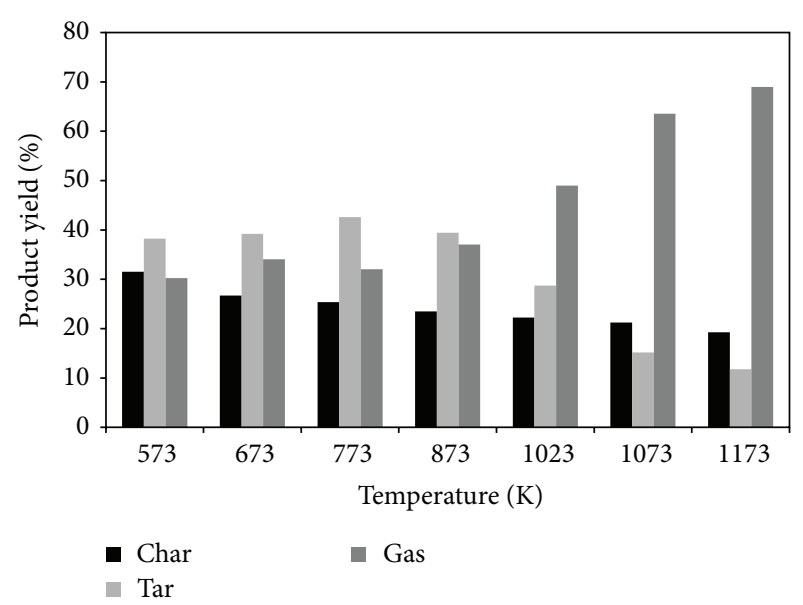

Figure 6: Percentage of product yields as char, tar, gas, and unreacted reactant in different pyrolysis temperature $(\mathrm{K})$.

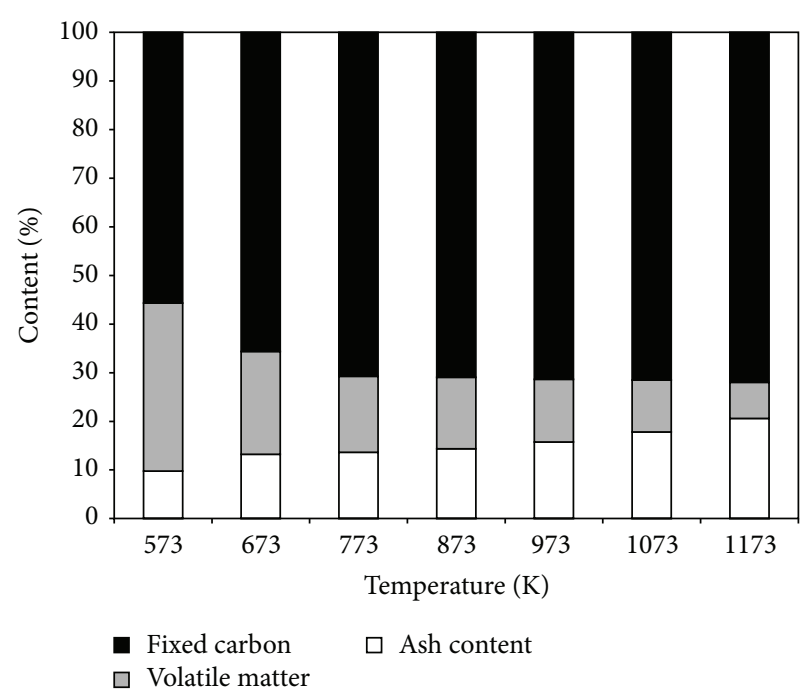

Figure 7: Percentage of volatile, ash, and fixed carbon present in char obtained at different pyrolysis temperatures.

\subsection{Products Characterization}

4.2.1. Proximate Analyses of Char. Proximate analyses of char obtained at different pyrotemperatures from $573 \mathrm{~K}$ to $1173 \mathrm{~K}$ are shown in Figure 7.

Proximate analysis of char sample has been done to measure the fixed carbon that is present in it. From this figure, it may be inferred that volatile content of char gradually decreases with temperature, while contents of fixed carbon and ash show increasing pattern with temperature. The fixed carbon and ash content of char product increased with temperature from 70.72 and $13.61 \mathrm{wt} \%$ at $773 \mathrm{~K}$ to 71.97 and $20.58 \mathrm{wt} \%$ at $1173 \mathrm{~K}$, respectively. While volatile matter of char product decreased from 15.66 to $7.44 \mathrm{wt} \%$ at 773 to $1173 \mathrm{~K}$.

4.2.2. Chemical Characterization of Product Yield. The empirical formulas of pyroproducts obtained at different pyrolysis 
TABLE 4: Empirical formula of char and pyro-oil.

\begin{tabular}{lcc}
\hline Temperature (K) & Char yield & Tar yield \\
\hline 573 & $\mathrm{C}_{3} \mathrm{H}_{2} \mathrm{O}$ & $\mathrm{CH}_{2} \mathrm{O}$ \\
673 & $\mathrm{C}_{3} \mathrm{HO}$ & $\mathrm{CHO}$ \\
773 & $\mathrm{C}_{6} \mathrm{H}_{3} \mathrm{O}$ & $\mathrm{CHO}_{2}$ \\
873 & $\mathrm{C}_{4} \mathrm{HO}$ & $\mathrm{C}_{3} \mathrm{HO}_{3}$ \\
973 & $\mathrm{C}_{5} \mathrm{HO}$ & $\mathrm{C}_{3} \mathrm{HO}_{3}$ \\
1073 & $\mathrm{C}_{6} \mathrm{HO}$ & $\mathrm{C}_{3} \mathrm{HO}_{3}$ \\
1173 & $\mathrm{C}_{7} \mathrm{HO}$ & $\mathrm{C}_{2} \mathrm{HO}_{4}$ \\
\hline
\end{tabular}

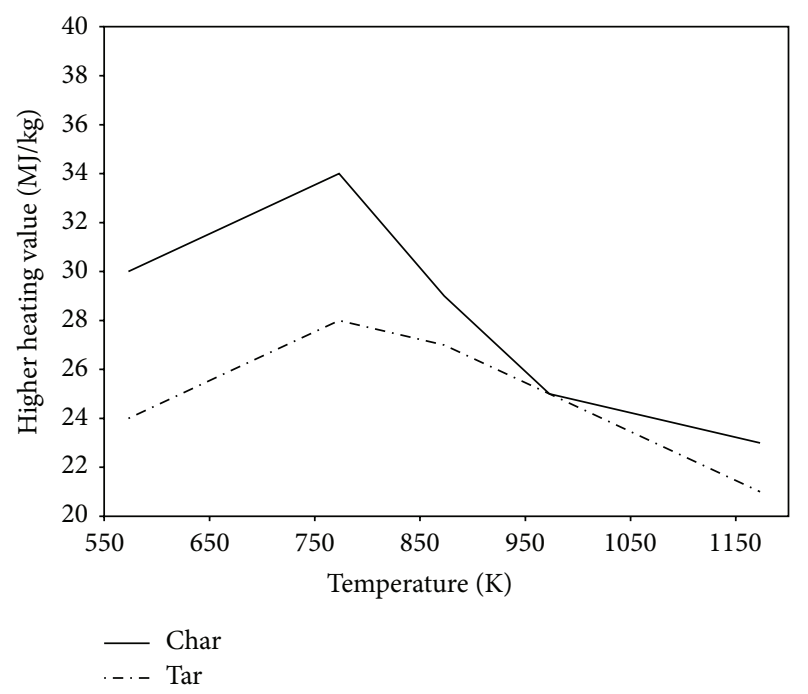

FIGURE 8: Pattern of higher heating values of pyro-oil and char at different pyrolysis temperature.

temperatures are listed in Table 4. It was clear from the table that the char products became carbon rich with the rise of pyrolysis temperature. The ratio of $\mathrm{H} / \mathrm{C}$ decreased with the higher temperature. On the other hand, the pyrooil became highly oxygenated with the rise of temperature. The ratio of $\mathrm{H} / \mathrm{C}$ decreased with the higher temperature. At initial temperatures, namely, 573,673 , and $773 \mathrm{~K}$, the $\mathrm{H} / \mathrm{C}$ ratios of pyro-oil were 14,9 , and 5 , respectively. Beyond this temperature, the ratio of $\mathrm{H} / \mathrm{C}$ of pyro-oil was similar to alkenes/cycloalkanes $(\sim 2)$.

4.2.3. Effects of Pyrolysis Temperature on Higher Heating Values of Product Yield. The higher heating values of char and tar yield of different pyrolysis temperature are determined using the bomb calorimeter given in Figure 8. The higher heating value of char increases gradually from 30 to 34 $\mathrm{MJ} / \mathrm{Kg}$ as the temperature increases from $573 \mathrm{~K}$ to $773 \mathrm{~K}$. Beyond $773 \mathrm{~K}$, the higher heating value decreases from 34 to $23 \mathrm{MJ} / \mathrm{Kg}$ as the temperature is changed from $873 \mathrm{~K}$ to $1173 \mathrm{~K}$. Pattern of temperature dependence of higher heating value of tar is also similar to that of char. This may be justified by the fact that fraction of carbon in char increases as the temperature increases up to $773 \mathrm{~K}$, beyond which char further participates in heterogeneous reactions with gaseous product. In case of tar, fraction of volatile components increases with
TABLE 5: Main atomic groups and structure of pyro-oil.

\begin{tabular}{|c|c|c|}
\hline Wavenumber $\left(\mathrm{cm}^{-1}\right)$ & Infrared spectrum & $\begin{array}{l}\text { Atomic groups and } \\
\text { structures }\end{array}$ \\
\hline $3200-3700$ & O-H stretching & Hydroxyl \\
\hline $2800-3000$ & $\mathrm{C}-\mathrm{H}$ stretching & $\begin{array}{l}\text { Aliphatic } \\
\text { structures }\end{array}$ \\
\hline $1650-1770$ & $\mathrm{C}=\mathrm{O}$ stretching & Carbonyl \\
\hline $1610-1680$ & $\mathrm{C}=\mathrm{C}$ stretching & Oliefinic structures \\
\hline $1450-1600$ & $\mathrm{C}=\mathrm{C}$ stretching & $\begin{array}{l}\text { Aromatic } \\
\text { structures }\end{array}$ \\
\hline $1420-1480$ & $\mathrm{C}-\mathrm{H}$ bending & $\begin{array}{l}\text { Aliphatic } \\
\text { structures }\end{array}$ \\
\hline $1360-1430$ & $\begin{array}{l}\mathrm{O}-\mathrm{H} \text { and } \mathrm{C}-\mathrm{H} \\
\text { bending }\end{array}$ & $\begin{array}{c}\text { Hydroxyl, acid, } \\
\text { phenol, olefins, and } \\
\text { methyl }\end{array}$ \\
\hline $1200-1300$ & $\mathrm{C}-\mathrm{O}$ stretching & Unsaturated ethers \\
\hline $1000-1200$ & $\begin{array}{l}\text { C-H out-of-plane } \\
\text { blending }\end{array}$ & $\begin{array}{l}\text { Aromatic } \\
\text { structures }\end{array}$ \\
\hline
\end{tabular}

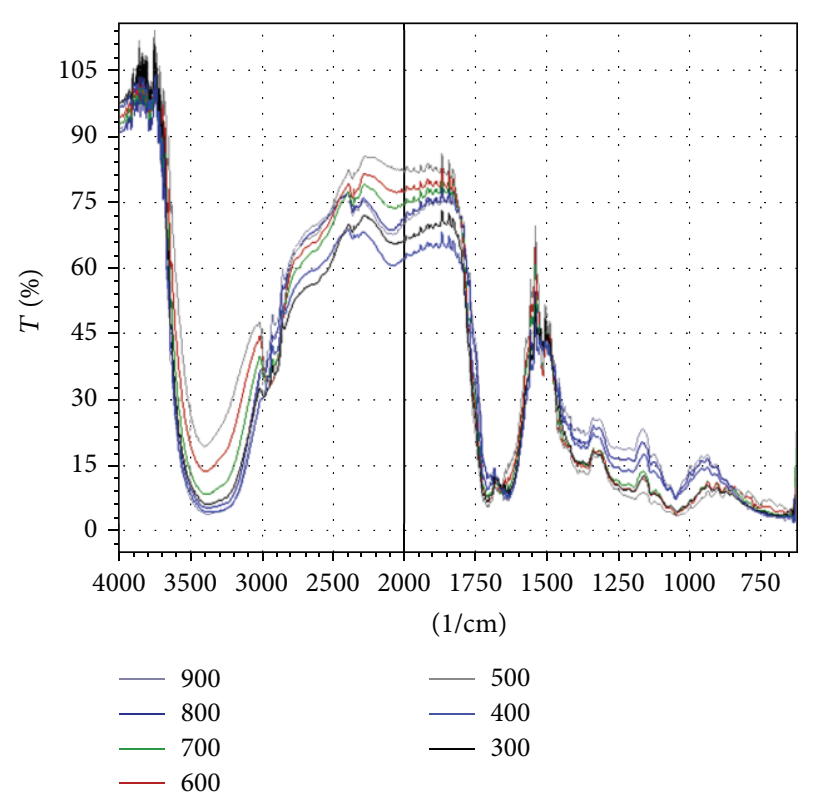

FIGURE 9: FT-IR spectrum of pyro-oil obtained at different pyrolysis temperatures.

the temperature, resulting in the increase of higher heating value up to $773 \mathrm{~K}$. At temperatures above $773 \mathrm{~K}$, secondary cracking of tar takes place causing decrease in higher heating value of tar.

4.2.4. FT-IR Analyses of Pyro-Oil. The FT-IR spectra of pyro-oils obtained at different temperatures from pyrolysis of newspaper waste feedstock are provided in Figure 9. Band assignments of IR spectrum of pyro-oil, which are summarized in Table 5, indicate that the pyro-oil contains a number of atomic groupings and structures.

It appeared from Figure 9 that the intensity of spectrum of pyro-oil has changed with the increase of temperature. 
At higher temperature, the hydrogen bonded $\mathrm{OH}$ stretching decreased due to the loss of phenolic or alcoholic groups of the pyro-oil [21, 24].

\section{Conclusion}

In the present investigation, pyrolysis of newspaper has been studied in the temperature range of $573 \mathrm{~K}$ to $1173 \mathrm{~K}$. FT-IR analyses of pyro-oil obtained at different reaction temperatures have been done. The effects of pyrolysis temperature on higher heating value and ratio of $\mathrm{H} / \mathrm{C}$ of pyro-oil and char have been discussed. These properties of the pyrolysis products can be used as fundamental data for the design of a pyrolysis process for biomass wastes. The system has been mathematically modeled in a deterministic way incorporating the deactivation phenomenon. A deactivation model representing the deactivation rate as a nonlinear function of activities has been found to be successful to explain the reaction engineering behaviour of the system.

\section{Nomenclature}

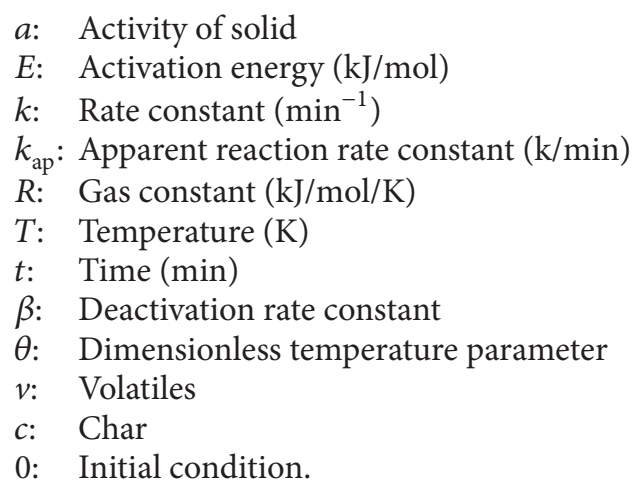

\section{Conflict of Interests}

The authors declare that there is no conflict of interests regarding the publication of this paper.

\section{Acknowledgment}

The authors gratefully acknowledge Council of Scientific \& Industrial Research (CSIR), India, for their financial support.

\section{References}

[1] G. Q. Lu, J. C. F. Low, C. Y. Liu, and A. C. Lua, "Surface area development of sewage sludge during pyrolysis," Fuel, vol. 74, no. 3, pp. 344-348, 1995.

[2] W. Iwasaki, "A consideration of the economic efficiency of hydrogen production from biomass," International Journal of Hydrogen Energy, vol. 28, no. 9, pp. 939-944, 2003.

[3] M. N. A. Bhuiyan, K. Murahami, and M. Ota, "On thermal stability and chemical kinetics of waste newspaper by thermogravimetric and pyrolysis analysis," Journal of Environment and Engineering, vol. 3, pp. 1-12, 2008.
[4] L. Li, H. Zhang, and X. Zhuang, "Pyrolysis of waste paper: characterization and composition of pyrolysis oil," Energy Sources, vol. 27, no. 9, pp. 867-873, 2005.

[5] C.-H. Wu, C.-Y. Chang, C.-H. Tseng, and J.-P. Lin, "Pyrolysis product distribution of waste newspaper in MSW," Journal of Analytical and Applied Pyrolysis, vol. 67, no. 1, pp. 41-53, 2003.

[6] S. Ogawa, H. Mizukami, Y. Bando, and M. Nakamura, "The pyrolysis characteristics of each component in municipal solid waste and thermal degradation of its gases," Journal of Chemical Engineering of Japan, vol. 38, no. 5, pp. 373-384, 2005.

[7] C. H. Wu, C. Y. Chang, and J. P. Lin, "Pyrolysis kinetics of paper mixtures in municipal solid waste," Journal of Chemical Technology and Biotechnology, vol. 68, pp. 65-74, 1997.

[8] L. Sorum, M. G. Gronli, and J. E. Hustad, "Pyrolysis characteristics and kinetics of municipal solid wastes," Fuel, vol. 80, no. 9, pp. 1217-1227, 2001.

[9] M. N. A. Bhuiyan, M. Ota, K. Murakami, and H. Yoshida, "Pyrolysis kinetics of newspaper and its gasification," Energy Sources Part A: Recovery, Utilization and Environmental Effects, vol. 32, no. 2, pp. 108-118, 2010.

[10] J. Zheng, Y.-Q. Jin, Y. Chi, J.-M. Wen, X.-G. Jiang, and M.-J. Ni, "Pyrolysis characteristics of organic components of municipal solid waste at high heating rates," Waste Management, vol. 29, no. 3, pp. 1089-1094, 2009.

[11] C. H. Wu, C. Y. Chang, and J. P. Lin, "Pyrolysis kinetics of paper mixtures in municipal solid waste," Journal of Chemical Technology and Biotechnology, vol. 68, no. 1, pp. 65-74, 1997.

[12] S. Luo, B. Xiao, Z. Hu, S. Liu, Y. Guan, and L. Cai, "Influence of particle size on pyrolysis and gasification performance of municipal solid waste in a fixed bed reactor," Bioresource Technology, vol. 101, no. 16, pp. 6517-6520, 2010.

[13] M. E. Sánchez, M. J. Cuetos, O. Martínez, and A. Morán, "Pilot scale thermolysis of municipal solid waste. Combustibility of the products of the process and gas cleaning treatment of the combustion gases," Journal of Analytical and Applied Pyrolysis, vol. 78, no. 1, pp. 125-132, 2007.

[14] A. N. García, R. Font, and A. Marcilla, "Kinetic study of the flash pyrolysis of municipal solid waste in a fluidized bed reactor at high temperature," Journal of Analytical and Applied Pyrolysis, vol. 31, pp. 101-121, 1995.

[15] H. Jørgensen, J. B. Kristensen, and C. Felby, "Enzymatic conversion of lignocellulose into fermentable sugars: challenges and opportunities," Biofuels, Bioproducts and Biorefining, vol. 1, no. 2, pp. 119-134, 2007.

[16] P. T. Williams and S. Besler, "The influence of temperature and heating rate on the slow pyrolysis of biomass," Renewable Energy, vol. 7, no. 3, pp. 233-250, 1996.

[17] S. Bandyopadhyay, R. Chowdhury, and G. K. Biswas, "Thermal deactivation studies of coconut shell pyrolysis," The Canadian Journal of Chemical Engineering, vol. 77, no. 5, pp. 1028-1036, 1999.

[18] R. Ray, P. Bhattacharya, and R. Chowdhury, "Simulation and modeling of vegetable market wastes pyrolysis under progressive deactivation condition," Canadian Journal of Chemical Engineering, vol. 82, no. 3, pp. 566-579, 2004.

[19] A. Sarkar and R. Chowdhury, "Reaction kinetics and product distribution of slow pyrolysis of Indian textile wastes," International Journal of Chemical Reactor Engineering, vol. 10, no. 1, pp. 1-22, 2012.

[20] A. Sarkar, B. Mondal, and R. Chowdhury, "Mathematical modeling of a semibatch pyrolyser for sesame oil cake," Industrial 
and Engineering Chemistry Research, vol. 53, no. 51, pp. 1967119680, 2014.

[21] A. Sarkar, S. Dutta, and R. Chowdhury, "Mustard press cake pyrolysis and product yield characterization," International Journal of Scientific \& Engineering Research, vol. 4, no. 8, 2013.

[22] A. Sarkar and R. Chowdhury, "Studies on catalytic pyrolysis of mustard press cake with $\mathrm{NaCl}$," International Journal of Engineering Sciences \& Research Technology, vol. 3, pp. 90-96, 2014.

[23] J. A. Menéndez, A. Domínguez, M. Inguanzo, and J. J. Pis, "Microwave pyrolysis of sewage sludge: analysis of the gas fraction," Journal of Analytical and Applied Pyrolysis, vol. 71, no. 2, pp. 657-667, 2004.

[24] R. K. Sharma, J. B. Wooten, V. L. Baliga, X. Lin, W. G. Chan, and M. R. Hajaligol, "Characterization of chars from pyrolysis of lignin,” Fuel, vol. 83, no. 11-12, pp. 1469-1482, 2004. 


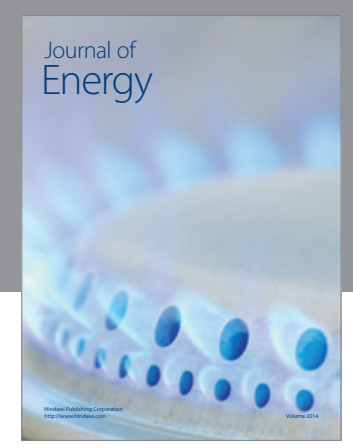

Journal of

Industrial Engineering
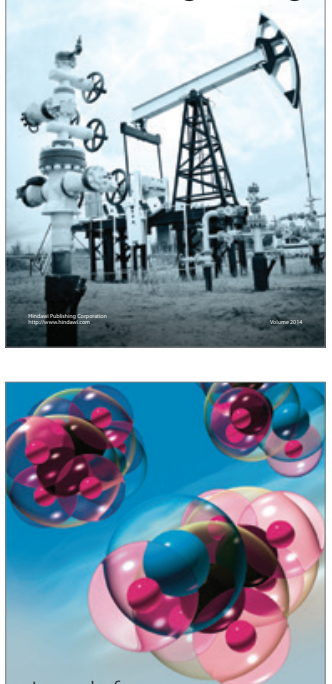

Fuels
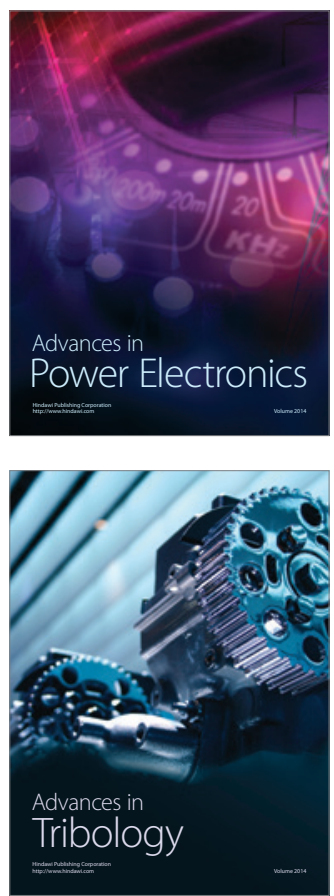

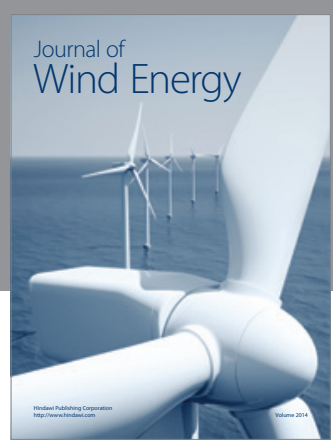

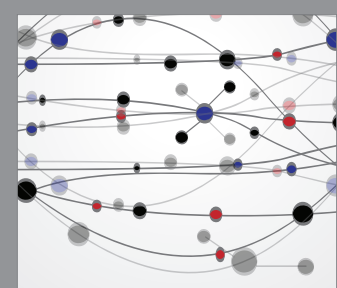

The Scientific World Journal

Submit your manuscripts at http://www.hindawi.com

Journal of

Structures
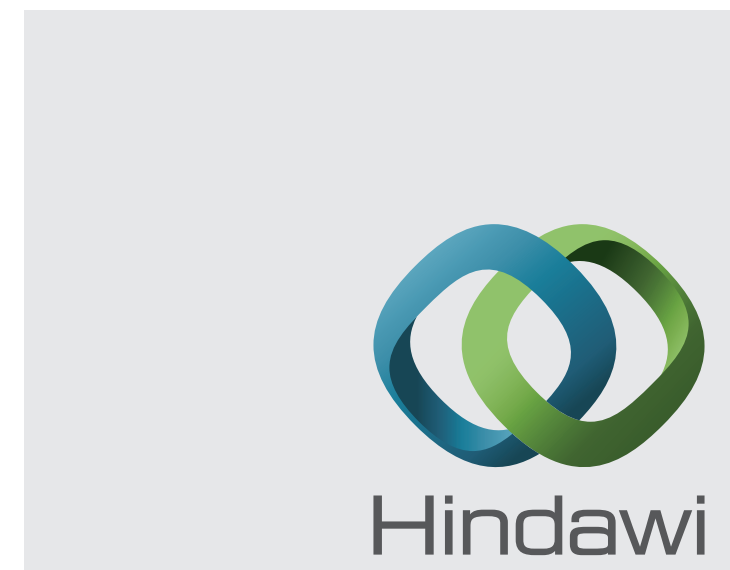

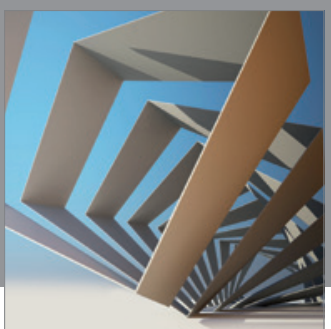

Rotating

Machinery
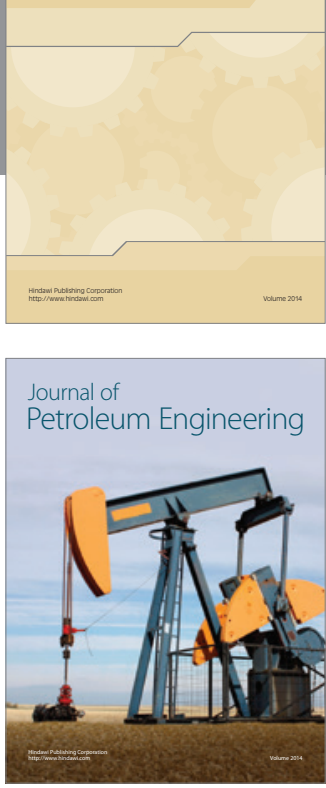

Journal of

Solar Energy
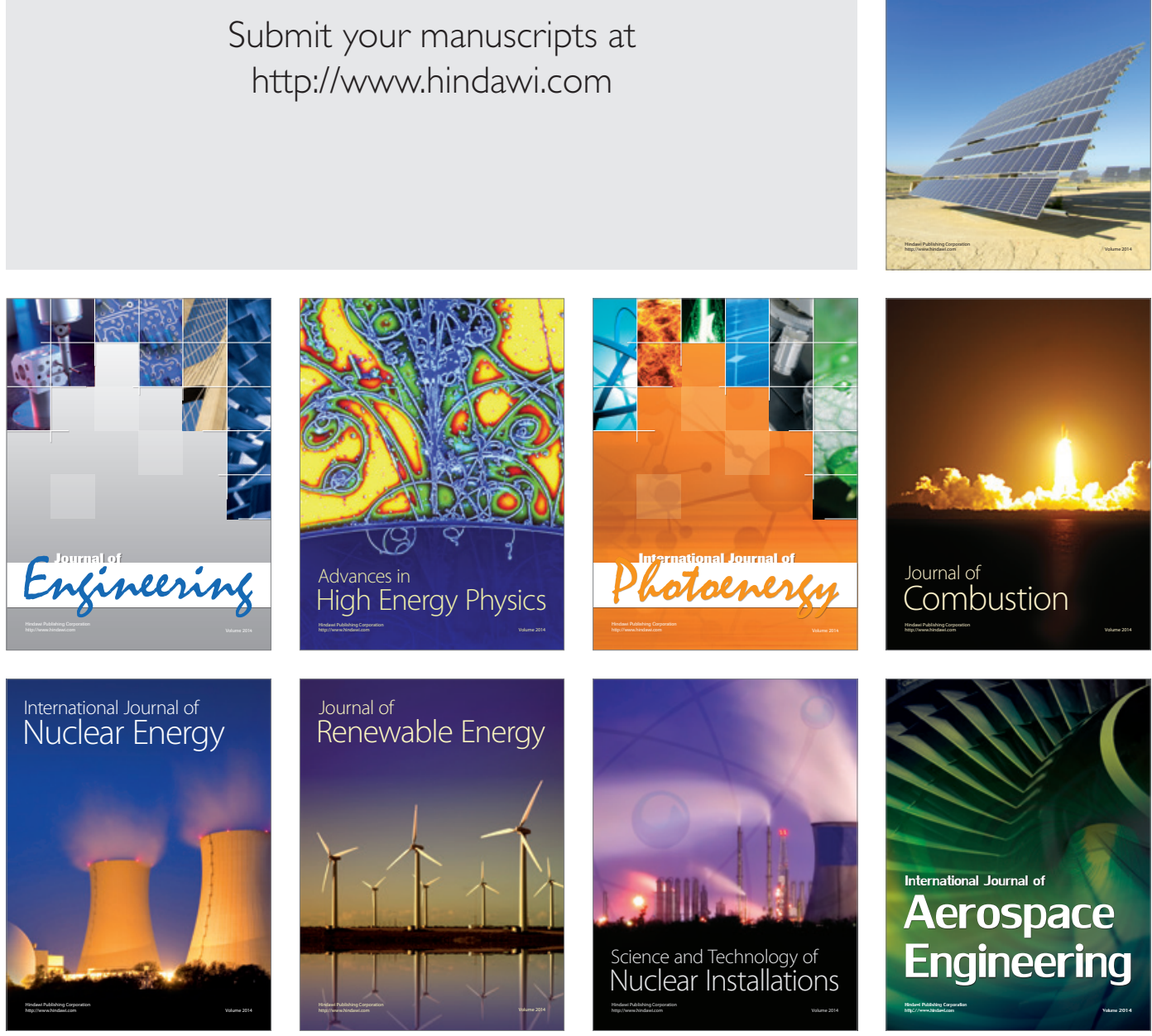